\section{Retinal capillary microaneurysms}

\section{Correction of erroneous attribution: Bader not Bowman}

In my Bowman Lecture of $1965^{1}$ I reported that Sir William Bowman was the first person to have described and illustrated retinal microaneurysms in 1857, in the earliest Pathology Report Book of Moorfields Eye Hospital (1857-1872) (Fig. 1). This claim was subsequently quoted elsewhere in the literature (e.g. Wise et al., ${ }^{2}$ Law $^{3}$ and others). This was of some interest in that it predated by 19 years the first published description by Mackenzie and Nettleship (1876). ${ }^{4}$ None of the handwritten and illustrated reports in the earliest Report Book was signed, so that the attribution to Bowman was made on the following criteria:

1. William Bowman was on the staff of Moorfields at that time (Assistant Surgeon, 1846; Full Surgeon, 1851; retired, 1876).

2. The excellent quality of the miniature sketches in the Report Book* correspond closely to the drawings by Bowman reproduced in his classical work on the kidney and muscle.

3. Bowman was also famous for his interest in the microanatomy and pathology of the eye.

4. The handwriting in the Report Book corresponds very closely to the specimens obtained of his writing during this period.

5. It was widely supposed that Bowman had been responsible for the microscopical examination of pathological specimens during his time at Moorfields.

I came to doubt my belief on reading Law's book on The History and Tradition of the Moorfields Eye Hospital, vol. II (1975), ${ }^{5}$ wherein there appeared a list of the Curators in charge of pathology at the hospital. Bowman was not among them. The first Curator during the period of the relevant part of the Report Book was Dr Charles Bader (1857-67). I then found, by looking through old contemporary journals, that drawings of the quality and minuteness of those in the Report Book were common to many

*The figures in Bader's textbook were, of course, copied from those of Bader's original drawings by his lithographer Mr E. Erxleben. They were, in fact, completely accurate copies.
NORMAN ASHTON

writers at that time, and also in ophthalmology, notably by Hulke and Nettleship (Curator 1871-73). Reference to an article by Bader (1860-61) ${ }^{6}$ showed that he also was a competent artist - including excellent microsketches. On further study, I found that handwriting at that time, being based on copperplate writing learnt at school, tended to be less individualistic than today and was often very similar from different hands. Finally I obtained a book written by Charles Bader: The Natural and Morbid Changes of the Human Eye and their Treatment $(1868)^{7}-$ drawings by C. Bader. Plate II of this publication shows three figures $(5,6$ and 14$)$ that were clearly taken from the drawings in the Pathology Report Book (p. 91a), and fig. 2 on this plate corresponds to a drawing on p. 100A. As an example of the above, my Fig. 2 shows a photograph of a drawing of 'aneurysmal dilatations' in the Pathology Report Book (p. 91a) that was obviously reproduced in Bader's textbook (plate II, Fig. 5), as shown in my Fig. 3.

I therefore conclude that Charles Bader and not William Bowman was responsible for the drawings in this book up to p. 97 and for the first known recorded note and illustrations of retinal microaneurysms (p. 60; see my Fig. 1). I apologise for having made a false attribution, especially to those who have quoted me.

\section{Charles Bader}

Charles Bader was born in Germany in 1827 in the Grand Duchy of Baden, where he was educated. During the revolution of 1848 he left Germany and settled in London where he qualified MRCS (Eng) and LSA (London). It is not clear what ophthalmological experience he had acquired, but in Germany he had profited from the leadership of von Graefe and Helmholtz. He was said to be 'skilled in the use of the ophthalmoscope' (Treacher Collins, 1929, p. 110). ${ }^{8}$ In any event, in 1857 he was appointed the first Curator and Registrar to Moorfields Eye Hospital (by then 'The Royal London Ophthalmic Hospital') with responsibility for reporting upon the microscopical appearances of pathological specimens and for keeping a register of such examinations. Hence the first volume of reports, which he began, with his 


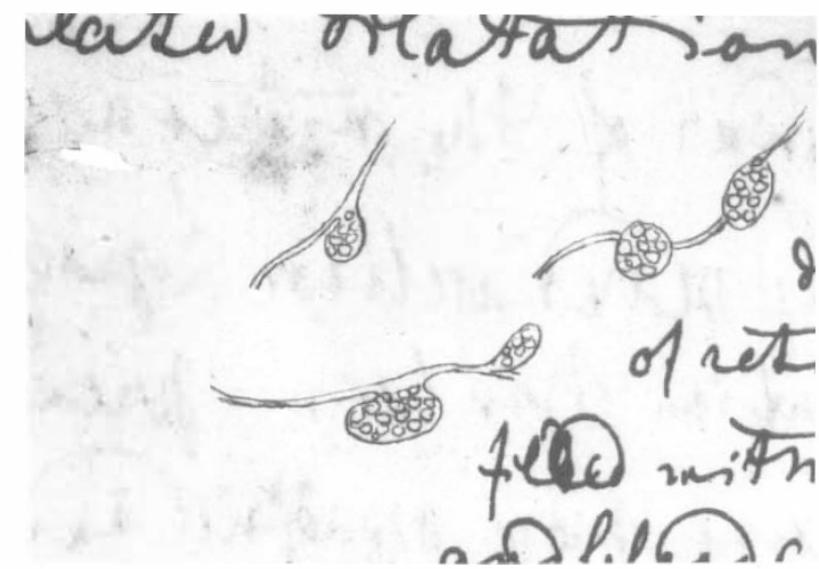

Fig. 1. Drawing on p. 60 of the Pathology Report Book (1857) - the first known illustration of retinal microaneurysms as seen in an 'old inflamed eye' injured at birth (male, aged 39 years), and showing 'sacculated dilatations of retinal capillaries filled with red fluid and blood corpuscles'. This particular sketch is not reproduced in Bader's textbook.

descriptions and exquisite drawings through 97 pages, continued presumably until he retired from the Curatorship in 1867. (It is odd that no special knowledge or experience in pathology was required for these important duties, then or for

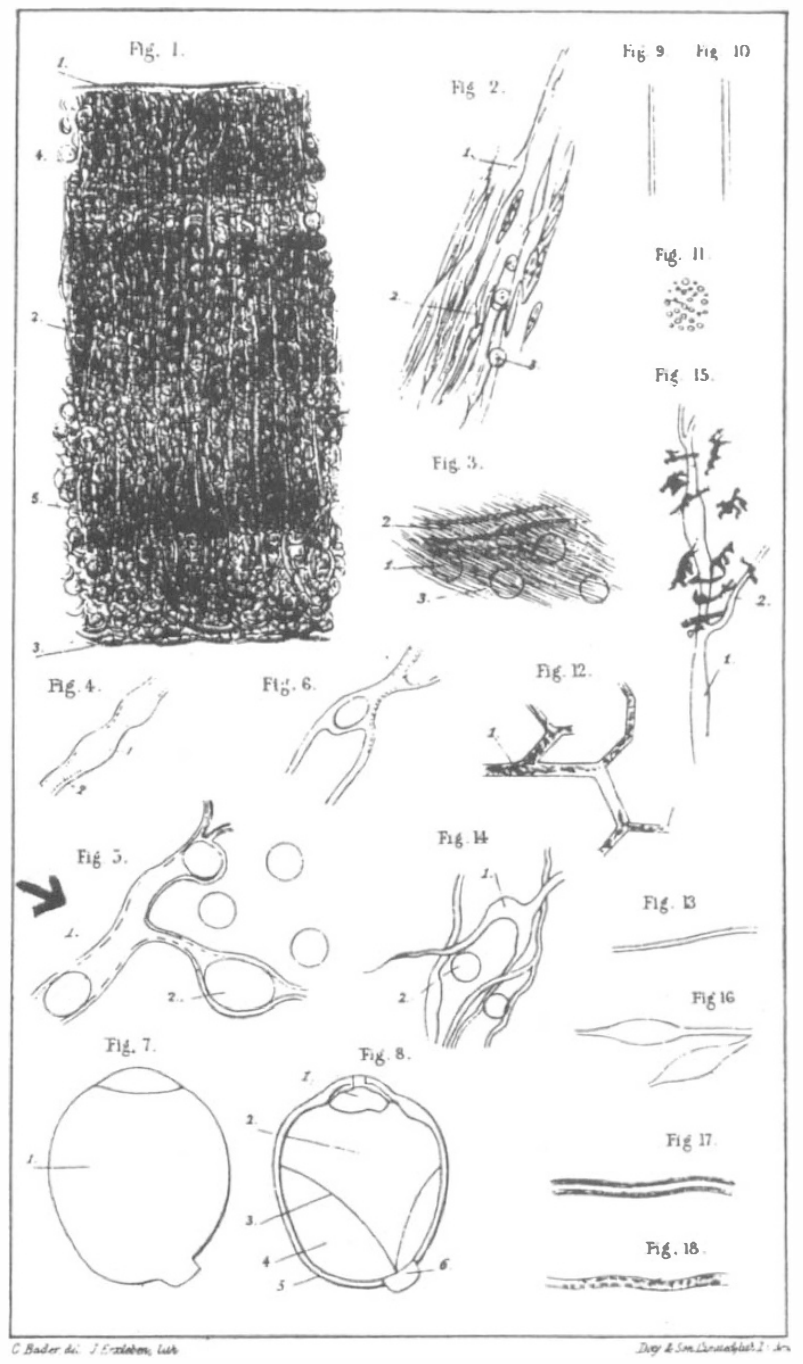

Fig. 3. Plate II from Bader's textbook. Note that his fig. 5 (arrow) is clearly a reproduction of the drawing in the Pathology Report Book (cf. Fig. 2 above), thus establishing the identity of their origin.

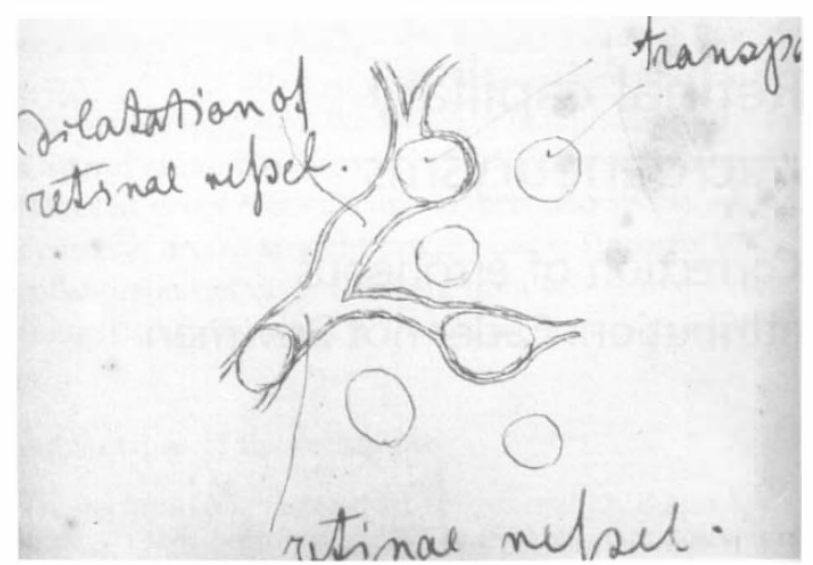

Fig. 2. Drawing on p. 91a of the Pathology Report Book showing 'aneurysmal dilatations' on a retinal capillary from a case of 'purulent ophthalmia' in a baby. Compare with Fig. 3.

the next 90 years. The post of Curator was always awarded to the most junior 'resident' ophthalmologist, as a testing ground for his election to the surgical staff. Other notable Curators were Edward Nettleship, E. Treacher Collins and George Coats.)

In 1861 Bader was appointed Assistant Ophthalmic Surgeon to Guy's Hospital and was promoted full Surgeon in 1873. He retained this post for nine years, during which time he was, as usual, most industrious, and helped to build a large and thriving eye department, operating with great skill on as many as 700 patients a year and acquiring a large private practice. He contributed some 14 articles to the Guy's Hospital Reports, and several others to the Royal London Ophthalmic Hospital Reports, which were largely concerned with ophthalmoscopical studies of normal and diseased eyes.

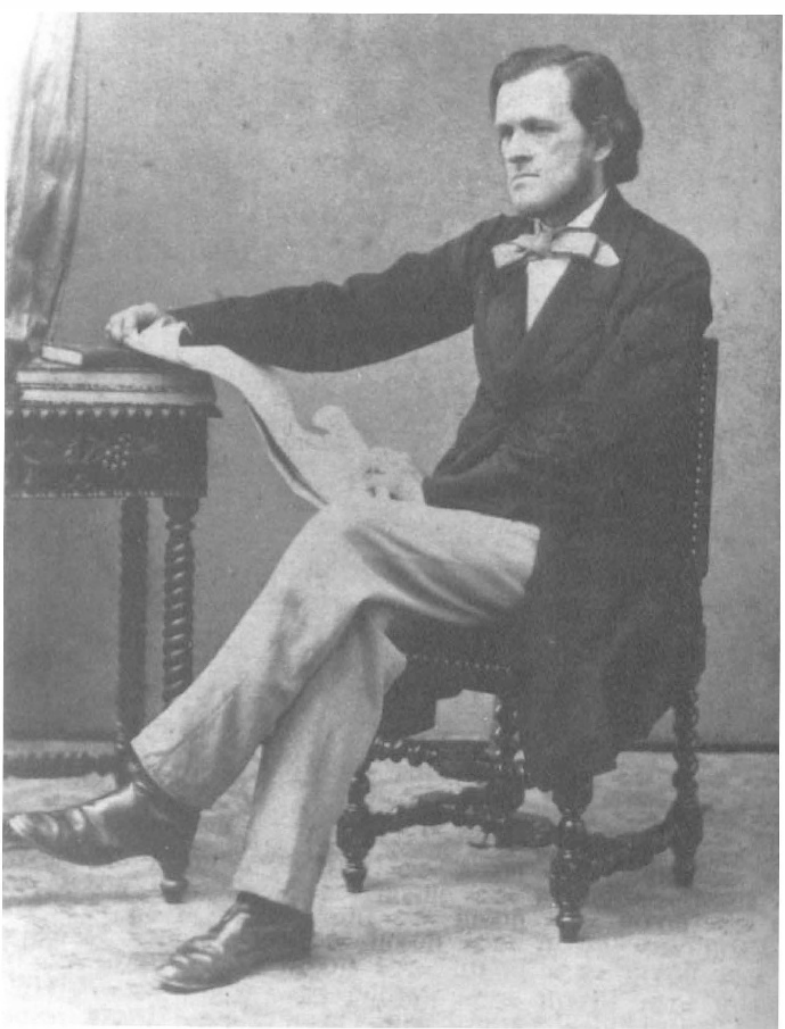

FIg. 4. Charles Bader, 1862, age 35 years. (Photograph by courtesy of Mr A. Basner, Wills Library, Medical School Building, Guy's Hospital, London.) 
In 1868 he published his book to which I have already referred - The Natural and Morbid Changes of the Human Eye illustrated by his drawings from the Pathology Report Book.

Curiously, Bader was never elected to the surgical staff of Moorfields Eye Hospital, suggesting that for some reason he was not wholly acceptable to his colleagues, possibly because his medical and ophthalmological training had not followed the orthodox stages required. Nevertheless, he was highly regarded and on his retirement in 1882 he was made a Consulting Ophthalmic Surgeon to Guy's Hospital.

He retired to his country property at Stoke Ferry, Norfolk, where he bred horses, cattle and sheep. Here he died aged 72 on 13 February 1899.

\section{References}

1. Ashton $\mathrm{N}$. The blood retinal barrier and vasoglial relationships in retinal disease. Bowman Lecture. Trans Ophthalmol Soc UK 1965;85:199-230.
2. Wise GN, Dollery CT, Henkind P. The retinal circulation. Diabetic retinopathy. New York: Harper \& Row, 1971: Ch. 15, see p. 422.

3. Law FW. History of ophthalmology. Sir William Bowman. Surv Ophthalmol 1974-5;19:302-7, see p. 306.

4. Mackenzie S (Eye pathology by Nettleship E). A case of glycosuric retinitis, with comments. 1876. Royal London Ophthalmic Hospital Reports 1877; vol 9, pt II:134-57.

5. Law FW. The history and traditions of the Moorfields Eye Hospital. Vol II. London: HK Lewis, 1975:283.

6. Bader C. Royal London Ophthalmic Hospital Reports 1860-61, vol 3. See plate XII (un-numbered sheet of illustrations, figs. I-VIII).

7. Bader $C$. The natural and morbid changes of the human eye and their treatment. C. Bader (Ophthalmic Assistant Surgeon to Guy's Hospital, London). Trübner \& Co., 1868. Drawings by Bader. Lithographs by E Erxleben, 2 Coram Street, Russell Square, and Day \& Son, London (plates I-IV).

8. Collins E Treacher. The history and traditions of the Moorfields Eye Hospital. Vol I. London: HK Lewis, 1975:283. 